\title{
Media frames of the Ontario Safe Streets Act: assessing the moral panic model
}

\author{
Michael Bates \\ This study was conducted under the supervision of Professor Bill O'Grady, \\ Department of Sociology, College of Social and Applied Human Sciences, \\ University of Guelph, Guelph, Ontario, Canada
}

\begin{abstract}
This paper assesses the "moral panic" framework of Stanley Cohen with reference to panhandling and squeegeeing in Ontario. There are four general tenets of the moral panic model, three of which can be said to have been documented in the case of panhandling in Ontario: a recognized threat (panhandling), a rise in public concern, and punitive control mechanisms established to eliminate the threat. This paper argues that the fourth tenet, a stereotypical presentation of the moral threat to the social order, has not been systematically analyzed, and therefore that is the task of this paper. Specifically, this paper examines the framing used by the mainstream print media in Ontario to construct the panhandling/squeegeeing problem. Articles and letters to the editor were sampled from two mainstream Ontario newspapers, the Toronto Star and the Ottawa Citizen, to examine the mainstream media's framing of panhandling and squeegee cleaning. This sample was taken between 1995 and 2005, a timeframe which revolves around the implementation of the Ontario Safe Streets Act 2000, which is recognized as the punitive control mechanism designed to eliminate the threat of panhandling. The findings of this paper lead to the conclusion that panhandling in Ontario during the implementation of the Ontario Safe Streets Act does not constitute a classic moral panic by virtue of the role the media played. However, the evidence that punitive control mechanisms were established absent the support of the mainstream media suggests that a deeper understanding of the role of mainstream media as well as political interests is required with respect to framing moral panics.
\end{abstract}

$\mathrm{F}^{\circ}$ or years sociologists have argued that the mass media plays a key role in shaping and/or reflecting public opinion[1,2]. There are two opposing perspectives about the role the media plays in contributing to social change. One perspective suggests that the media is an independent body of organizations which are critical of the status quo and are active in instigating social change. The alternative perspective views the media as a tool used by those in the upper echelons of society to maintain the status quo by promoting its economic and political agendas.

The latter of these two views, which is informed by a political economy perspective, argues that those who own and control the mass media (economic elites/bourgeoisie) also have an influence, if not a strong presence, in the political decision making process. The elements of political decision making power and control of media outputs has the effect of legitimating political decisions and actions of economic elites within a public forum.

Associated with this perspective, which will be termed "media hegemony" [3] but with more nuanced undertones, is the "moral panic" framework of Stanley Cohen[4]. Although the framework has been tested, amended and revised over the past thirty-five years or so, the general tenets of the model have endured and remain relatively intact today. ${ }^{*}$ There are

four broad characteristics of a moral panic: a condition, episode, person or group of persons labeled as threatening societal values; increased public concern over the perceived threat; the media presents the threat in a stereotypical fashion; and punitive control mechanisms are created to reduce or eliminate the threat [4]. A key feature of a moral panic is that the level and character of the threat, as reported by the media, is normally exaggerated and reflects a stereotypical perspective that is contrary in terms of how the behavior or condition is measured by official statistics or the harm that is invoked on society. For instance, in a study of a moral panic that took place in the USA in the 1980s over so called "crack babies", claims in the media were made suggesting that the infants of crack addicts were born addicted to crack and had to undergo detoxification and would later face major learning disabilities. As a result of these and other drug related fears, incarceration rates rose astronomically in the United States for people convicted of drug related offences. However, research and statistics later showed that such claims about crack babies were greatly misleading and exaggerated [13]. This shows how media reporting can support, add legitimacy to, and in some cases instigate social change. Goode and Ben-Yehuda suggest that the media, as an "interest group" contributing to public

*Examples of moral panics include: mods and rockers[4]; attacks on women[5]; violence against the elderly[6,7];

school shootings[8]; Satanism[9]; muggers[10]; drug users[11]; and adolescent sexuality[12]. 
discourse, can and do make claims which can become moral panics, at times independent of elite interests[14]. This opposes the concept of media hegemony.

With respect to the research methods used by those who study moral panics, a common practice is to include excerpts from the media (e.g. newspapers, magazines, and television) to support Cohen's assumption that the media plays a key role in creating such social constructions. Normally such evidence appears in the form of images and quotations which are taken from the press as an indication of how the media have framed the labeled deviants or threat responsible for the panic. However, the question that remains is: how representative are these examples when they are used to support the assumption that the mass media in general props up and supports moral panics? Past research on moral panics has not always systematically analyzed the mainstream media and the role it plays in generating moral panics.

This is the general issue that will be explored in this paper. Events surrounding the Ontario Safe Streets Act (OSSA) will be examined within the context of how the mainstream press in Ontario (The Ottawa Citizen and the Toronto Star) covered stories related to the law which prohibited activities such as "aggressive" panhandling and solicitation on Ontario road ways. Consistent with the propositions of the moral panic model addressed above, the way in which mainstream media framed its coverage of the OSSA, panhandling, and squeegeeing will be examined. Was the coverage presented in a manner which supports and promotes the position taken by the Ontario conservative government who passed this law and order legislation in 1999, or was coverage critical of the Act? Articles and letters to the editor from the Toronto Star and the Ottawa Citizen (two large mainstream newspapers in Ontario) will be used as data for this analysis. The central question that will guide this research is: how do the Toronto Star and Ottawa Citizen frame the activities of panhandling and squeegee cleaning in Ontario in relation to the implementation of the Ontario Safe Streets Act?

\section{The Ontario Safe Streets Act}

Critics have suggested that the Canadian state has adopted a general pattern of neoliberal public policies which are responsible for anti-panhandling bylaws, legislation such as the OSSA, and a zero tolerance policing philosophy [15, 16]. One characteristic of neo-liberalism is that it directs attention towards minimizing alternatives to wage labor [17] and seeks to have people produce income through "legitimate" means (i.e. employment within the labor market) regardless of pay and working conditions. It can be argued that homeless people, as a distinct population, are generally perceived to be lazy, drug addicted, and criminogenic and thus do not contribute to economic activity in society - a major requirement for citizenship, according to supporters of neo-liberalism. For these reasons it has been argued that "safe streets" types of laws have emerged in several cities across the country (e.g. Vancouver, Calgary,
Winnipeg and Montreal) that seek to abolish acts related to income generation which are not regulated within the confines of the labor market, such as panhandling and/or squeegee cleaning [16]. Interestingly, this is also characteristic of moral panic theory which suggests that social control mechanisms are designed not only to eliminate a perceived threat but to preserve and reassert dominant societal values (such as "legitimate" economic gain) [9].

When the Ontario government proposed the OSSA in 1999 it alleged to have done so because of the claims it received from authorities and the public that panhandlers and "squeegee kids" were disrupting and aggravating pedestrians/motorists, intimidating them and making the streets unsafe $[15,18]$. This constitutes a rise in public concern which is central to the moral panic model. A short time afterwards, Ontario Cabinet Minister Jim Flaherty gave a statement at Queen's Park that: “Today marks an important step in keeping Ontario's streets safe for law-abiding citizens" and "The people of Ontario have the right to walk on the streets and use public places without fear or intimidation" [19]. This shows that the laws, as well as the rhetoric used to promote them, clearly separates the homeless population from the rest of the "law abiding" citizenry.

In many respects the development and implementation of the OSSA is in keeping with Cohen's notion that key elements of moral panics are the legal mechanisms that are put into place in order to control groups who are a perceived threat to the moral order. There is no doubt that some of the press at the time did portray squeegee cleaners as a menace to society and as a group in need of control [20].

However, as stated previously, little is known about the role that the mainstream media played in this series of events that could be interpreted as a moral panic. To clarify, "mainstream" is used to describe the largest circulation papers in Ontario. The Sun, for instance, was not selected due to its marginal circulation compared to the Star and Citizen. However, it could be deemed "mainstream" in the sense that it tends to be right winged and therefore potentially supportive of legislation such as the OSSA, but this is not how mainstream is defined here.

How did large circulation newspapers cover the OSSA? Did they, as would be predicted by the moral panic framework, demonize and present negative images of panhandlers and squeegee kids which would be consistent with and supportive of the government's decision to outlaw squeegee cleaning and "aggressive" panhandling in Ontario in 2000? It is important to systematically understand how the mainstream press covered this topic. If it did so in such a way that "squeegee kids" and their like were demonized, and calls for control were made loud and clear, then Cohen's interpretation of the role that the media plays in a moral panic is supported. However, if mainstream press coverage is generally unsupportive, and does not endorse a law and order frame related to topics covering "squeegee kids",

**The Toronto Sun and the a.m. "talk" radio station CFRB are two media outlets which supported the OSSA. 
panhandlers and the OSSA, then the role that the media plays in the creation of what could be described as a moral panic will need to be re-examined. The Methods section of this paper will describe the manner in which these questions will be empirically addressed.

\section{RESULTS AND DISCUSSION}

\section{Results}

The graphs constructed from the analysis of the newspapers were prepared in order to examine how the media framed homelessness surrounding the drafting and implementation of the Ontario Safe Streets Act. As such, the focus when reading the following graphs is between the years 1998 and 2001, when concern about panhandling and squeegeeing was at its highest in Ontario. It should also be noted that the percentages in each of the four graphs are calculated by year. For example, if there are eight welfare framed articles in a year with ten sampled articles in total then the percentage of welfare framed articles for that year will read as eighty percent.

Figure 1 shows that that the welfare frame dominates throughout the ten year period, but that it is somewhat less prevalent in the beginning, middle, and end of this period. The charity frame occurs less frequently than the welfare frame and fluctuates over the ten year period. Of the three frames included in Figure-1, the law and order frame is the least prevalent. However, it rose slightly in 1998, the year preceding the introduction of the OSSA.

The data in Figure 2 clearly indicates that the welfare frame consistently dominated the ten year period. Although at relatively low frequencies, there are a steady percentage of articles espousing law and order frames from 1997 through to 2001 (when the OSSA was introduced and implemented). However, a total absence of law and order framing occurred for the remainder of the time period. The charity frame is present consistently from 1998 to 2000 and is most apparent from 2002 to 2004. After comparing the data from Figures 1 and 2, the frames found in the articles from the Citizen and the Star are very similar: the welfare frame dominated news stories in both publications.

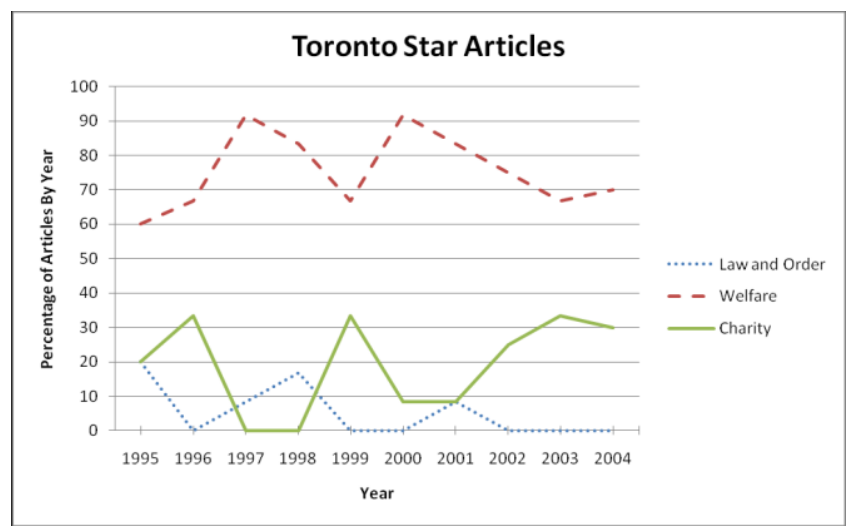

Figure 1. Frequency and type of frame for Toronto Star articles

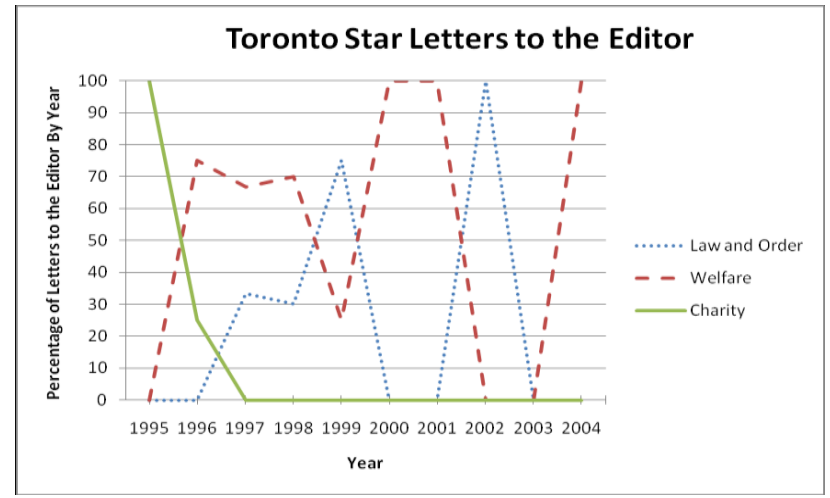

Figure 2. Frequency and type of frame for Ottawa Citizen articles

Unlike the previous two graphs that examined news articles, when data are examined in letters to the editor Figure 3 shows that while welfare framing is consistently present throughout the ten year period (with the exception of 2002 and 2003), law and order framing is noticeably present between 1997 and 1999, and again in 2002. In fact, it overtakes welfare framing in 1999 and 2002. Charity framing is present during 1995 and 1996 but is absent for the rest of the time period.

Figure 4 shows that both welfare and law and order framing peak and valley frequently throughout the ten year time period. Conversely, the charity frame was consistently absent until a slight rise in 2004. Similar to the previous figures which examined the articles, law and order framed letters to the editor for Figure-4 grew in number from 19982000. After this time law and order framed letters continued to fluctuate but were consistently present until 2004.

Comparing the articles with the letters yields noticeable differences. It appears that the framing found in the articles, for both newspapers, holds a more stable pattern over time. For instance, the welfare frame dominates the Toronto Star articles over the ten year period, hovering between sixty and ninety percent. Conversely, the pattern for the welfare frame in the Toronto Star letters to the editor fluctuates widely over the ten year period. Such variation can be found for the law and order frame and, to some extent, the charity frame as well. The stability of framing is also noted in the Ottawa Citizen articles although, as with the Toronto Star, the stability is absent from the Ottawa Citizen letters to the editor.

Thus, when comparing the articles with the letters to the editor the most obvious difference is that the letters to the editor graphs contain more drastic rises and falls with respect to both welfare frames and law and order frames. Secondly, there are a higher percentage of law and order frames present in the letters to the editor compared to the articles; this occurs for both newspapers. The law and order frame dominates the welfare frame for two years in the Toronto Star letters to the editor while it falls quite short of overcoming the welfare frame in the Toronto Star articles. The same is true of the Ottawa Citizen; the law and order 


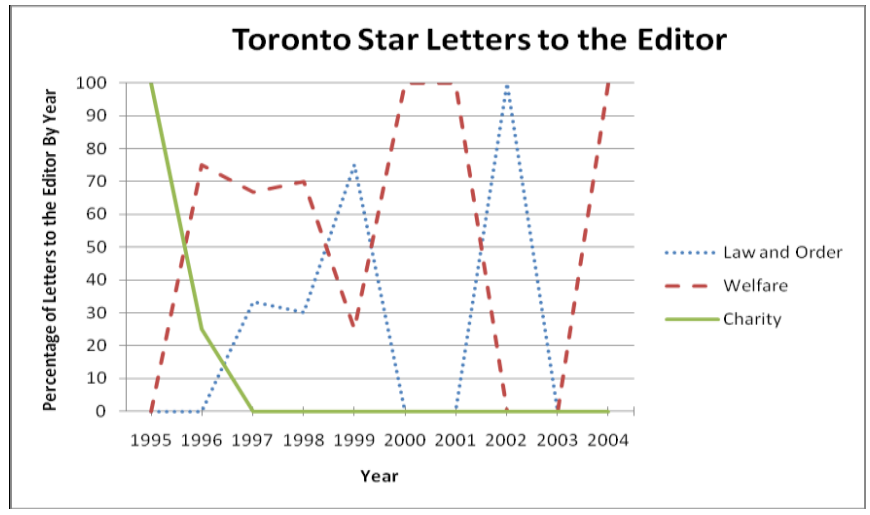

Figure 3. Frequency and type of frame for Toronto Star letters to the editor

frame dominates the welfare frame for three years in the letters to the editor while it is far from overcoming the welfare frame in the articles. A third distinction is that the letters to the editor have a lower percentage of charity frames when compared to the articles.

\section{Discussion}

The results obtained in this analysis provide evidence that the mainstream press in Ontario is not hegemonic as has been previously argued in some of the moral panic literature. While there is some evidence to suggest that law and order frames rose around the passage of the OSSA (particularly letters to the editor), overall the articles were consistently welfare oriented while the letters to the editor fluctuated a great deal.

Hence, the results in this study indicate a lack of support for what is known as "media hegemony"[3] or the "dominant ideology" model [21], both of which have been associated with the role played by the media in constructing moral panics. Media hegemony asserts that forms of news media perpetuate the status quo by presenting the cultural views of the dominant class [3]. As discussed earlier, this concept is rooted in Marxist thought by stressing that the dominant class controls media outputs for its benefit. Rather, according to this analysis, the mainstream print media operates more autonomously than media hegemonists have asserted. According to the moral panic model, both articles and letters to the editor should have taken a law and order frame most often, especially during the time period surrounding the implementation of the OSSA. When viewed overall, the data collected in this study shows that the welfare frame was the most dominant. Although, it should be noted that the newspapers used in this study, especially the Toronto Star, have a history of espousing news stories from a liberal perspective and therefore the findings could be deemed predictable. Had this study used different print media for analysis such as the Toronto Sun or the Globe and Mail, results may have differed. Therefore, the findings of this study are somewhat limited in that they do not contain a comprehensive analysis of print media that promote different ideologies. However, if ideological tendencies of media outlets remain relatively stable over time regardless of the ideals and actions of governing powers, this in itself suggests that they operate somewhat autonomously.

As the results indicate, there is a much higher prevalence of law and order framing contained within the letters to the editor than within the articles. Prior research suggests that some social problems tend to take a more liberal or "benevolent" frame within the articles or columns section of a newspaper [22]. This of course depends on the newspaper, as some tend to be more liberal minded then others, as are the Toronto Star and Ottawa Citizen [18]. Why then does there appear to be a much higher prevalence of law and order framing in the letters to the editor in these two newspapers?

First of all, in order for letters to be published it necessitates that they have been submitted to the papers by interested readers. It is possible that all the letters to the editor relating to panhandling were published in the newspapers examined. However, this is unlikely because any large circulating paper, like the Toronto Star or the Ottawa Citizen, publishes only a portion of the letters it receives[23]. It follows that editorial decisions are required to determine which letters get published. Findings from other research show that editors are often concerned with presenting a balanced debate within letters to the editor, especially over a contentious social issue [23, 24]. A problem such as aggressive panhandling and/or squeegee cleaning is very contentious and clear cut; either you side with the homeless or against them. That is why the letters to the editor in this study show more of a balance between law and order framing and welfare framing than the articles. It is also most likely why there is an absence of charity framed articles.

The findings obtained in this study suggest that the role that the mainstream press took over the concern about squeegee kids and aggressive panhandling does not constitute the role that the media should play according to a classic moral panic scenario. The development of squeegeeing and aggressive panhandling as a social problem

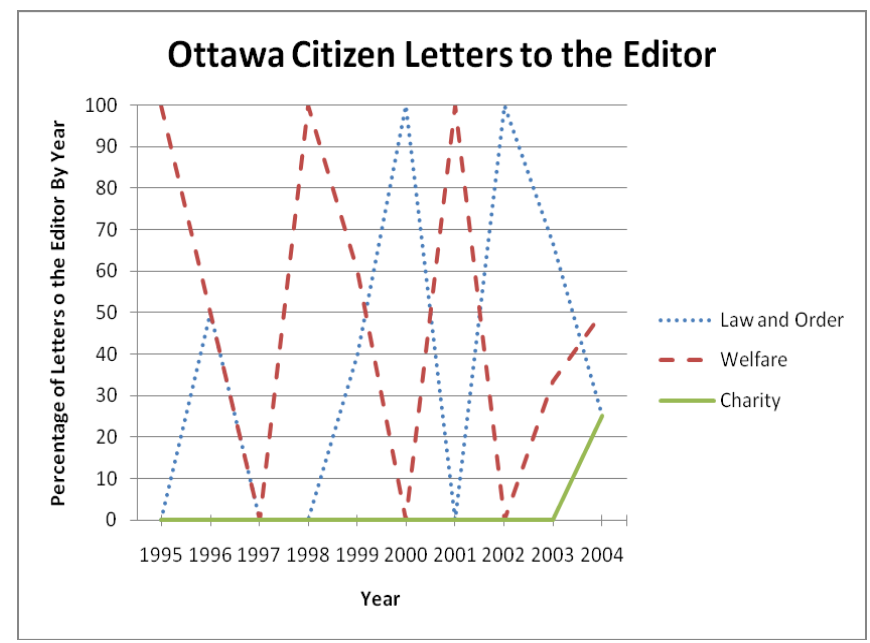

Figure 4. Frequency and type of frame for Ottawa Citizen letters to the editor 
emerged in a fashion that was similar to the moral panic model - there was an increase in public concern over squeegee kids and aggressive panhandlers in the late 1990s and this appeared in some media outlets [18]. It is also likely that such concern played a role in leading the Ontario government to implement control mechanisms with the formulation of the OSSA. A missing dimension of what could be considered a moral panic was the absence of a stereotypical portrayal of squeegee kids and panhandlers by the mainstream press. The mainstream press, rather than sensationalizing and perpetuating existing notions of aggressive panhandlers, as would be the case in a classic moral panic scenario, took the side of the homeless and reported the problem using a predominantly welfare minded frame. Instead of portraying the homeless as aggressive and deviant, the Star and the Citizen framed homeless people as victims of the misguided perceptions/actions of the state and public.

The reason why the press took a predominately welfare frame may be related to common media practices. In cases of media reports, journalists often must get information from outside sources. In particular, stories that relate to crime are often retrieved from the police $[25,26]$ and therefore police have a great deal of influence of what frame the story will take by virtue of their control of information and how it is presented. Any news relating to violence or crime is also shown to be particularly entertaining for readers and is often reported in the media $[4,5]$. However, news stories relating to panhandling present another highly accessible source, notably the panhandlers themselves. This opposing view often has a personal dynamic that addresses life on the streets, hardships faced and intimidation by police that makes for a more sensational news story.

This decision to oppose a law and order framing, as has been discussed, is due to the media being at least semiautonomous from the influence of elites but it is further argued here that the media sided with the homeless because it recognized the newsworthiness in opposing the stereotypical portrayal of homeless people.

In cases of moral panics there are clear victims and offenders that often represent the epitome of innocence and malevolence [9]. Offenders in moral panics include Satanists, criminals and psychopaths. Victims include children, the elderly and women. In the case of panhandling, both the public and the Ontario government framed the problem as one of the offender (the aggressive and possibly intoxicated panhandler or squeegee kid) intimidating/threatening the victim (the law abiding citizen on the street or in their car). In the case of violence against the elderly Sacco argues that the news industry realized the dramatic value in portraying the elderly as victims of street predators [6]. It is argued here that the media recognized the newsworthiness in opposing the stereotypical frame of the violent, aggressive panhandler and presenting the homeless population as victims of an oppressive society.

\section{Methods}

Using a random stratified sample this study collected articles and letters to the editor from the Toronto Star and the Ottawa Citizen from the period beginning January 1, 1995 and ending January 1, 2005. This time period was used because the focal point of this study is the Ontario Safe Streets Act, the enforcement of which began in January of 2000. This allows an equal amount of time before and after the Act's implementation in which to analyze relevant articles and letters. This ten year period is further reduced to three equal periods in order to compare how frames of panhandling and squeegee cleaning changed over the entire duration. Period one is from 1995-1998; period two is from 1999-2001; and period three is from 2002-2004. Both articles and letters were used because they are distinctly different from one another. Articles are generally written by those employed by the newspaper or by those who work on a freelance basis. Letters to the editor come from the paper's readership. Given the two different formats, including both units of analysis will provide for a more comprehensive assessment of the role that the mainstream press played in framing events before, during and after the implementation on the OSSA.

The key search words "panhandling", "squeegeeing", and "Ontario Safe Streets Act" were used when electronically searching the citation and document text of the papers. Using systematic stratified random sampling, the articles and letters were separated according to the month and year of their publication; at which point one article and letter was randomly selected from each grouping. This resulted in ninety articles from the Toronto Star, along with twenty-nine letters (some months had no relevant articles/letters). Sixty-five articles were retrieved from the Ottawa Citizen, along with twenty-three letters. This sampling method was utilized in order to provide the researcher with a relatively equal number of articles and letters from two separate newspapers over the ten year period. Organizing the data is this fashion allowed for an analysis which was able to compare frames between the newspapers and also compare frames between articles and letters to the editor-both over a ten year time period.

As was mentioned, the Toronto Star and the Ottawa Citizen are the newspapers analyzed in this study. The Star and the Citizen were chosen because they both cater to the largest number of people in two of Ontario's largest cities: Toronto and Ottawa. While the findings obtained from these newspapers obviously cannot be generalized to the Ontario press in general, both are representative of the mainstream press as, combined, both papers have a Saturday circulation of over 750,000 [27]. To give context, in 2001 the number of private dwellings in all of Ontario was 4,219,415 [28].

Three coding categories were used to analyze the data. The goal was to find common themes or frames that the newspapers used when reporting on the OSSA. The three coding categories which emerged from the analysis were: Law and Order, Welfare, and Charity. The Law and Order 
heading depicts frames that are consistent with, and generally advocate, a law and order policing approach directed towards panhandling and homelessness (including fines, arrests and forcible removal). Alternatively, the Welfare heading depicts frames that are a critique of the law and order approach and generally advocate a social welfare approach with state involvement to solve the problem of panhandling and homelessness. Charity, the third heading, refers to letters or news articles where the public is encouraged to donate to causes which support the less fortunate (e.g. food banks, the Salvation Army, etc.). Refer to Appendix A for two tables which define and provide examples of the three frames used in this study.

\section{CONCLUSIONS}

Panhandling in Ontario during the implementation of the OSSA cannot be designated the status of a classic moral panic due to the absence of stereotypical media portrayals of the established threat (the "aggressive" panhandlers). Although, it should be noted that even without this component there still appeared widespread concern from the public as well as quick responding legislative action, which was formed to mitigate the public anxiety caused by the perceived threat. This is fundamentally what a moral panic is about; social change and a reassertion of dominant moral values, all of which was accomplished without the support of mainstream media. This suggests that panhandling may be deemed a moral panic but that further understanding of political interests and decision making may be beneficial in this particular case as well as others to better understand politics role in creating/supporting moral panics in general.

It has been suggested that, based on the results of this study, there is little support for the idea that the mainstream press in Ontario played a role of perpetuating existing, stereotypical notions of panhandlers and squeegee cleaners in relation to the OSSA. Hence, it puts to question the notion that the mainstream media needs to be "on board" with state efforts to criminalize vulnerable populations. While the government of the time may have had the support of the tabloid press and from some callers and hosts from "talk radio" programs, by no means was it necessary to pass legislation to criminalize a "threat to the moral order" which had little support from the mainstream media. Given the findings of this study, it would be wise for future research that deals with moral panics to more closely consider the role of the mainstream media, and not only rely upon excerpts from peripheral, ideologically loaded commentators. In this particular case it would be prudent to further examine large circulation right winged media sources that reported on panhandling during this time period to gain a more comprehensive analysis of media output.

The role that the mainstream press played with regard to the OSSA involved two important elements. First, from a business perspective, the idea that the homeless make for better victims than offenders has more public appeal than presenting the homeless as group of criminals. Second, mainly due to the fact that most homeless people spend their time in public places, the media has the ability to access them directly for information should they decide to write a story on the topic. Speaking to a homeless person directly is more likely to invoke a conversation that focuses on the struggles of living on the streets, rather than how panhandlers are bad for business or tourism. For these reasons it would be more accurate to view the print media in Ontario as a semiautonomous capitalist enterprise, and not uncritical purveyors of the "dominant ideology".

This study has sought to contribute to an understanding of how the media contributes to social problems discourse using the case of panhandling. The media interprets and adds to discussion of current social problems on a daily basis and therefore contains endless information for sociological analysis. Continued analysis of how and why the media interprets various social problems is important in understanding its complex structure and inner-workings. Analysis is also relevant in determining the media's ability to shape understandings of social problems and therefore shape the courses of action to remedy them.

\section{ACKNOWLEDGEMENTS}

The author would like to thank Professor Bill O'Grady for all his help in the formulation and development of this paper. The author would also like to thank the peer reviewers for their comments and suggestions which were much appreciated.

\section{REFERENCES}

1. Altheide, D. 1978. Newsworkers and Newsmakers: A Study in News Use. Journal of Contemporary Ethnography, 7(3), 359-378.

2. Ericson, R., \& Baranek, V. 1991. Representing Order. In Representing Order: Crime, Law, and Justice in the News Media (20-46). Toronto: University of Toronto Press.

3. Altheide, D. 1984. Media Hegemony: A Failure of Perspective. Public Opinion Quarterly, 48, 476-490.

4. Cohen, S. 1972. Folk Devils and Moral Panics: The Creation of the Mods and Rockers. Great Britain: Granada Publishing Limited.

5. Ericson, R., \& Voumvakis, S. 1984. News Accounts of Attacks on Women: A Comparison of Three Toronto Newspapers. Toronto, ON: University of Toronto.

6. Sacco, V. 2004. Violence and the Elderly. In J. I. Ross (Eds.), Violence in Canada (pp. 153-185). New Brunswick: Transaction Publishers.

7. Fishman, M. 1978. Crime Waves as Ideology. Social Problems, 25(5), 531-543.

8. Ferguson, C. 2008. The School Shooting/Violent Video Game Link: Causal Relationship or Moral Panic? Journal of Investigative Psychology and Offender Profiling 5(1-2), 25-37. 
9. DeYoung, M. 1997. Another Look at Moral Panics: The Case of Satanic Day Care Centers. Deviant Behaviour: An Interdisciplinary Journal, 19, 257-278.

10. Hall, S., Critcher, C., Jefferson, T., Clarke, J., \& Roberts, B. 1978. Policing the Crisis: Mugging, the State and Law and Order. London: Macmillan.

11. Ben-Yehuda, N. 1990. The Politics and Morality of Deviance: Moral Panics, Drug Abuse, Deviant Science, and Reversed Stigmatization. Albany: New York Press.

12. Lacombe, D., \& Barron, C. 2005. Moral Panic and the Nasty Girl. Canadian Review of Sociology and Anthropology, 42, 51-70.

13. Goode, E., \& Ben-Yehuda, N. 2009. Moral Panics: The Social Construction of Deviance $\left(2^{\text {nd }}\right.$ ed.). Chichester, U.K.: Wiley-Blackwell.

14. Goode, E., \& Ben-Yehuda, N. 1994. Moral Panics: Culture, Politics and Social Construction. Annual Review Sociology 20, 149-171.

15. Gordon, T. 2004. The Return to Vagrancy Law and the Politics of Poverty in Canada. Canadian Review of Social Policy 54, 34-57.

16. Gingrich, L. 2003. Constructing Identity and Drawing Lines: The Textual Work of Ontario's Safe Streets Act. Journal of Canadian Studies 37(4), 151-170.

17. Sears, A. 1999. The Lean State and Capitalist Restructuring: Towards a Theoretical Account. Studies in Political Economy, 59, 91-114.

18. Parnaby, P. 2003. Disaster Through Dirty Windshields: Law, Order and Toronto's Squeegee Kids. Canadian Journal of Sociology, 28(3), 281-307.

19. Ontario Ministry of the Attorney General. 2000. Press Release. Attention News Editors: Squeegeeing,
Aggressive Panhandling Outlawed Today. Retrieved from: www.newswire.ca/govemment/ontario/english/ releases/January2000/311c4335.htiln January 28, 2010.

20. Hermer, J., \& Mosher, J. 2002. Disorderly People: Law and Politics of Exclusion in Ontario. Halifax, Nova Scotia: Fernwood Publishing.

21. Ericson, R. 1991. Mass Media, Crime, Law, and Justice: An Institutional Approach. British Journal of Criminology, 31(3), 219-249.

22. Hoffman, L., \& Slater, M. 2007. Evaluating Public Discourse in Newspaper Opinion Articles. Journalism and Mass Communications Quarterly, 84(1), 58-74.

23. Page, B. 1996. Who deliberates: Mass media in modern democracy. Chicago: University of Chicago Press.

24. Hogan, J. 2006. Letters to the Editor in the "War on Terror": A Cross National Study. Mass Communication \& Society, 9, 63-83.

25. Doyle, A. 2006. How Not to Think About Crime in the Media. Canadian Journal of Crime and Criminal Justice, 48(6), 867-885.

26. Ericson, R., Baranek, P., \& Chan, J. 1989. Negotiating Control: A Study of News Sources. Toronto: University of Toronto.

27. Canadian Circulations Audit Board. 2009. Daily Newspaper Report for the 12 Month Period Ended December 2009. Retrieved on June 4, 2010 from: http://mediakit.thestar.ca/uploads/pdf/2010/circ/Toronto Star_CCAB_Audit_Report_Dec_2009.pdf .

28. Statistics Canada. 2001. Ontario Census 2001. Retrieved on October 20, 2011 from: http://www12.statcan.ca/english/census01/products/stan dard/prprofile/prprofile.cfm?G=35. 